\title{
Emotional Exhaustion in Graduate Students: The Role of Engagement, Self-Efficacy and Social Support
}

\author{
Julaine Rigg ${ }^{1}$, Jonathon Day ${ }^{2} \&$ Howard Adler ${ }^{2}$ \\ ${ }^{1}$ School of Business and Management, Morgan State University, Baltimore, Maryland, USA \\ ${ }^{2}$ School of Hospitality and Tourism Management, Purdue University, West Lafayette, Indiana, USA \\ Correspondence: Julaine Rigg, School of Business and Management, Morgan State University, 1700 E. Cold \\ Spring Lane, Baltimore, MD, 21251, USA. Tel: 1-443-885-4454. E-mail: Julaine.rigg@morgan.edu
}

Received: August 13, 2013

Accepted: September 22, 2013

Online Published: October 14, 2013

doi:10.5539/jedp.v3n2p138

URL: http://dx.doi.org/10.5539/jedp.v3n2p138

\begin{abstract}
Graduate students, particularly those based in research intensive universities are susceptible to exhaustion. The study utilized a quantitative approach to test the impact of student engagement, self- efficacy, and social support on college students' emotional exhaustion. A hierarchical regression approach was used for analysis. Findings demonstrated that students who were engaged, and self -efficacious were less exhausted from their studies. Social support especially from advisors was important in helping students cope with emotional exhaustion. Additionally, student engagement proved to be important as it partially mediates the advisor support- exhaustion relationship while fully mediating the self-efficacy- exhaustion relationship. Implications and suggestions for institutions of higher learning regarding intervention strategies to mitigate the exhaustion and burnout process were discussed.
\end{abstract}

Keywords: graduate students, emotional exhaustion, engagement, self-efficacy, support

\section{Introduction}

Management researchers have studied exhaustion and burnout extensively since the concept was introduced in 1974 by Freudenberger. Freudenberger (1974) conceptualized exhaustion as "to fail, to wear out, or become exhausted by making excessive demands on energy, strength, or resources" (p. 159). Burnout was linked to the continuous pressures of working with emotionally needy and demanding individuals (Jacobs \& Dodd, 2003) and Freudenberger emphasized emotional exhaustion as the result of continuous overwork and over-extension (Fives, Hamman \& Olivarrez, 2007).

Burnout was initially thought to occur in human services through three phases. First, there is emotional exhaustion that resulted from extensive demands placed on the employee. Second is depersonalization, which is the cultivating of cynicism and insensitivity toward people, including co-workers and customers. Third, there are feelings of low personal accomplishment, where employees feel frustrated and helpless (Riggio \& Porter, 2003; Schaufeli \& Bakker, 2004). Maslach and Leiter (1997) posited that burnout is related to various outcomes including physical exhaustion, insomnia, and increased drug and alcohol use. People who are experiencing burnout may have lower motivation, may become dissatisfied with the job, may be at risk for health issues, and may experience a decrease in efficacy. Arguably, the concept of burnout can be extended beyond human services in a business context and studies have indicated that students also are susceptible to burnout (Balogun, Helgemoe, Pellegrini, \& Hoeberlein, (1995; Gold, Bachelor \& Michael, 1989).

Since such initial research, additional research streams have examined the emotional aspects of burnout including emotional exhaustion, feelings of self efficacy, and social support. An increasing body of literature has placed emotional exhaustion as the principal dimension of burnout (Cordes \& Dougherty, 1993; Gaines \& Jermier, 1983; Maslach, 2003). Wright and Cropanzano (1998) cited Shirom (1989) who indicated that the 'core' meaning of burnout is evident in physical and psychological depletion that characterizes emotional exhaustion. Similarly, a study by Lee and Ashforth (1993) showed that emotional exhaustion played a pivotal role in the burnout process. Furthermore, emotional exhaustion is said to be the aspect of burnout that is more applicable to occupations not related to human services. This is as a result of its similarity to chronic fatigue unlike customer depersonalization and low accomplishment, emotional exhaustion can be generalized to other people who are 
experiencing fatigue (Gaines \& Jermier, 1983). Moore (2000) indicated that an emotionally exhausted person feels tired and fatigued, and lacks energy with depleted emotional resources.

Students who experience burnout are exhausted because of the physical and emotional demands of studying. They may have a cynical and decreased attitude regarding their studies. They also may feel incompetent (Schaufeli, Martinez, Marques Pinto, Salanova, \& Bakker, 2002). The graduate school experience is intensely stressful. The rigor of graduate degrees, personality, time limits, and demands from external and internal environments can exacerbate graduate students stress (Offstein, Larson, McNeill, \& Mwale, 2004). A study by Meier and Schmeck (1985) showed that burned-out students are uncaring and are bored by class routines. Studies about emotional exhaustion in employees indicated that employees endeavor to mitigate emotional exhaustion by removing themselves either temporarily or permanently from the work situation (Gaines \& Jerimer, 1983; Moore, 2000). Similarly, graduate students that are suffering from exhaustion may exhibit similar behavior.

Only a few studies to date have assessed the graduate student population (Hancock, 2002). Burnout of college students has been limited and focused mostly on those in supervisory and advisory roles, such as resident assistants (RAs) (Jacobs \& Dodd, 2003). Most studies that have looked at emotional exhaustion as the core of burnout have assessed it in organizational settings (e.g., Wright \& Cropanzano, 1998). Furthermore, there is a dearth of literature regarding university students' 'engagement' in their studies with only few known studies. (See, Lloren, Schaufeli, Bakker, \& Salanova, 2007; Schaufeli, et al. 2002; Schaufeli \& Salanova, 2007). Hence, the current study is one step in the direction to fill the gap in the literature regarding graduate student emotional exhaustion (the core of burnout) especially its relationship with engagement. The main purpose of the study is to evaluate empirically the influences of engagement, self efficacy, and social support on graduate student emotional exhaustion. Students who are emotionally exhausted and burnout may display an increase in absenteeism, lower motivation to engage in necessary school work, and may eventually dropout of college (Ramist, 1981). Golde (2005) indicated that at least $40 \%$ of students who begin a doctoral program fail to complete it. Golde (2005) further stated that there is little information available about the reasons students leave graduate programs. With graduate students susceptible to exhaustion, a study of this nature is timely to understand the ramifications of engagement, self efficacy, and the amount of support, on students' emotional exhaustion. Jacobs and Dodd (2003) indicated that many college students who request counseling may be burned out or experience some of its consequences.

\subsection{Literature and Hypotheses Development}

\subsubsection{Self Efficacy and Engagement}

Two characteristics closely related to emotional exhaustion are the absence of self-efficacy and engagement. Perceived self efficacy indicates a person's belief in his capabilities to execute necessary courses of action to achieve established attainments (Bandura, 1997). Various authors have studied the relationship between self efficacy and engagement. Self efficacy has been shown to have a positive relationship with engagement. In a study by Xanthopoulou, Bakker, Demerouti, and Schaufeli (2009) self efficacious employees experienced a higher level of engagement and may be more capable to meet demands they encounter in various situational contexts.

Schaufeli, Martinez, Pinto, Salanova, and Bakker (2002) studied university students in three countries and found strong correlations between self efficacy and engagement for all three samples. Schaufeli and Salanova (2007) found similarly high correlations between self efficacy and engagement in university students. A sample of students with higher self efficacy led to higher vigor and dedication (Llorens, Schaufeli, Bakker, \& Salanova, 2007). Thus, as students develop confidence in their beliefs about their abilities to meet their school demands, their levels of engagement in their studies may increase, where they feel energetic, dedicated, and engrossed in their studies to the point where it may become difficult for them to detach themselves easily. Accordingly, the following is proposed:

\section{H1: The higher the self- efficacy of graduate students, the higher their engagement levels}

\subsubsection{Self Efficacy and Emotional Exhaustion}

Many scholars of burnout have utilized self-efficacy theory (Friedman, 2003). As noted, self-efficacy is a personal resource which is capable of reducing burnout in individuals and may explain/determine job-related effectiveness (Luthans \& Peterson, 2002). Therefore, the greater a person's self-efficacy, the less stress and depression one will encounter in threatening or demanding environments, attributed to one's personal ability to cope (Bandura, 1997). Self-efficacy may act as a buffer against work stress and burnout (Schmitz, 2000). 
Research about teacher self efficacy and burnout supported that high self-efficacious teachers experience more satisfaction with the job and exhibited less burnout than less self efficacious teachers (Friedman, 2003; Schmitz, 2000). The effect of student-teachers' self-efficacy and burnout was studied by Fives, Hamman, and Olivarez (2007). At Time 1 and Time 2, they found that as student-teachers' levels of efficacy increase their burnout level decreased. In $\mathrm{n}$ a study of Management Information Systems college student burnout, Yang and Farn (2005) provided evidence that students who had higher levels of self efficacy exhibited lower levels of burnout. Selfefficacy is, therefore, negatively related to emotional exhaustion. The following is hypothesized:

\section{H2: The greater the self -efficacy of graduate students, the lower their level of emotional exhaustion.}

\subsubsection{Engagement and Emotional Exhaustion}

The concept of engagement is traced back to Kahn (1990) who defined personal engagement as "the harnessing of organization members' selves to their work roles" (p. 694). Engaged employees are involved physically in their tasks, cognitively alert, and emphatically connected to others (Kahn, 1990). Maslach and Leiter (1997) further argued that work engagement is situated at the opposite end of job burnout and is characterized by energy, involvement, and a sense of efficacy instead of emotional exhaustion, cynicism, and reduced professional efficacy.

Researchers such as Schaufeli, Salanova, Gonzalez-Roma, and Bakker (2002), whose definition is now the mostly widely used, defined engagement from a different approach (Attridge, 2009; Slåtten \& Mehmetoglu, 2011). Schaufeli and Bakker (2004) defined job engagement as "a positive, fulfilling, work-related state of mind characterized by vigor, dedication, and absorption" (p. 295). A person who is vigorous will persist at the job, even when the job is difficult. Meanwhile, a person expressing dedication will be enthused about the job, have pride, and is inspired with the job as a challenge. An absorbed individual will be happily engrossed in the task to the point where it may be hard for him/her to detach from the task. High work engagement has positive impact on organizational outcome: a reduction in intention to quit, increased commitment, and satisfaction (Harter, Schmidt, \& Hayes, 2002).

Burnout and engagement are each other's opposite, especially with relation to exhaustion and vigor/ cynicism and dedication (Schaufeli \& Bakker, 2004). Engagement and emotional exhaustion - the central quality of burnout - have been shown in empirical studies to be moderately negatively related (Schaufeli \& Bakker, 2004; Schaufeli, et al., 2002; Schaufeli \& Salanova, 2007). Considering that emotional exhaustion is negatively related to engagement, we propose the following hypothesis:

\section{H3: Graduate students who are more engaged in their studies will exhibit less emotional exhaustion.}

\subsubsection{Social Support and Engagement}

Social support means having people available who show they care about our wellbeing and on whom one may rely (Sarason, Levine, Basham, \& Sarason, 1983). Numerous scholars are studying the relationship between social support and work engagement. There is a positive relationship between the two constructs. Testing the role of job resources on engagement, Crawford, LePine, and Rich (2010) posited that job resources such as social support have a direct positive relationship with employees' work engagement.

Job resources such as support may increase individuals' motivational process which may impact employees' positive outcome in organizations. Job resources in the form of social support from colleagues and supervisor coaching increased engagement in a multi-sample of four service organizations (Schaufeli \& Bakker, 2004). Moreover, co-worker support was found to cause employees to feel vigorous and dedicated at work. Similarly, schools with more supportive principals were found to have more engaged teachers, even though support from friends and family did not significantly impact teachers' engagement levels. There is a scarcity of literature about engagement and support in general, especially regarding student populations. The following hypothesis is made based on support in organizational settings:

H4: The more support graduate students receive from (a) family, (b) friends, (c) spouse, and (d) advisors, the more likely they will be engaged in their studies.

\subsubsection{Social Support and Emotional Exhaustion}

Social support has been advanced as a resource that enables individuals to cope with stress and work demands (Bakker, Demerouti, \& Euwema, 2005; House, 1981). Several studies have shown that social support from supervisors, co-workers, significant others, friends and family may aid in alleviating burnout among individuals (Bakker, et al., 2005; Ito \& Brotheridge, 2003; Karatepe \& Olugbade, 2009; Klusmann, Kunter, Trautwein, Lüdtke, \& Baumert, 2008). Social support from advisors also has been found to have a significant impact on 
students' emotional exhaustion /burnout (Koekse \& Koeske, 1989; Yang \& Farn, 2005) For example, an unsupportive environment and lack of support from academic departments were given as reasons for students' stress and quitting graduate school. In a study by Johnson, Batia, and Haun (2008), one respondent in an interview regarding cause for quitting indicated the following:

"The people there weren't very supportive... the professors were more focused on their research than in teaching, and they really didn't have a lot of time for their students, and .... you didn't really get to know and spend time with the other students, so you didn't really have that kind of support and camaraderie."

Although there are overwhelming results showing the buffering effect of social support on burn out and stress-strain relationship, some studies have not found significance for some form of support. For example, Jacobs and Dodd (2003) only found a statistically significant relationship between social support from friends concerning college student burnout, with support from friends negatively related to burnout. Koeske and Koeske (1991) found insignificant relationships between social support from advisor, significant other, and parents on students' burnout on intention to quit: However, there was a significant finding for support from "other faculty". With overwhelming research showing the negative relationship between social support and burnout the following hypothesis is proposed:

H5: The greater the social support for graduate students from a) family, (b) friends (c) spouse and (d) advisor, the less their exhaustion.

\subsubsection{Mediation of Engagement}

Limited empirical evidence has been presented that examines the mediation of engagement between self efficacy and emotional exhaustion and between social support and emotional exhaustion in extant literature. Moreover, there is no known study that has tested these relationships in a university setting. From Hypotheses 1 through 5, it can be determined that engagement may act as a mediator in the relationship between self efficacy and emotional exhaustion and between social support and emotional exhaustion. Furthermore, engagement was found to mediate the relationship between job resources (social support from co-workers and supervisor coaching) and job consequences, such as intention to quit (Saks, 2006; Schaufeli \& Bakker, 2004) Intention to quit is normally a consequence of emotional exhaustion. Additionally, people who believed in their capabilities to perform their task and were optimistic showed increased levels of engagement (Xanthopoulou, et al., 2009), which may lead to a reduction in stress levels and burnout. Accordingly, self efficacy (personal resource) and social support (job resource) (Xanthopoulou, et al., 2009) will impact emotional exhaustion directly and indirectly through engagement. The following are proposed:

H6: Student engagement will mediate the relationship between self efficacy and emotional exhaustion.

H7: Student engagement will mediate the relationship between social support from (a) family, (b) friends (c) spouse, and (d) advisors and emotional exhaustion.

Based on the analysis of extant research the current research examines the relationships between self efficacy, social support, engagement, and emotional exhaustion. Determining the relationship among these factors may help us better understand why graduate student may become burnout and eventually add to the high attrition rate. A conceptual framework is presented in Figure 1 showing the research design. 


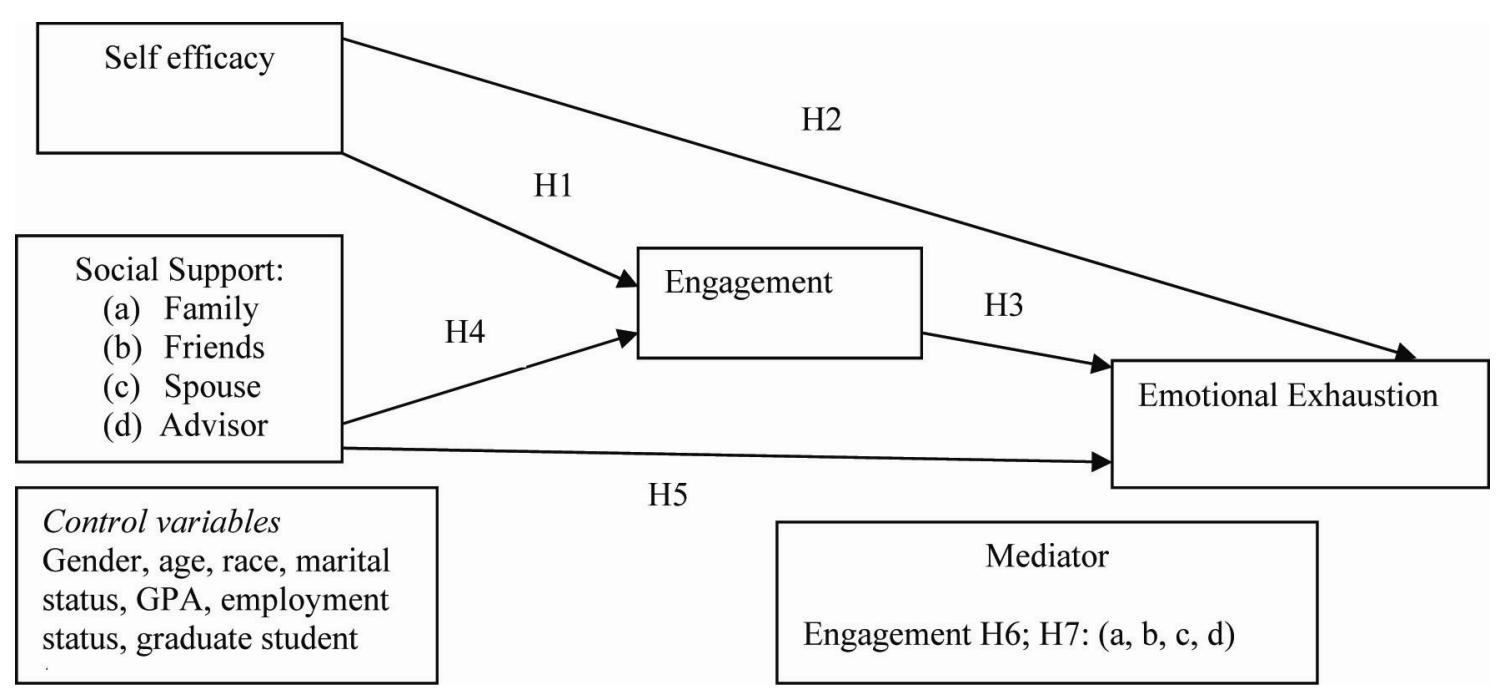

Figure 1. Conceptual framework

\section{Method}

\subsection{Research Participants}

The participants were graduate students enrolled in masters and doctoral studies at a research intensive university in the Midwestern region of the United States. Although the experiences and issues faced by masters and doctoral students differ to some extent, masters students were invited to participate since they constitute a part of the graduate student population. For example, doctoral students are known to have a higher attrition rate. The university has a culturally diverse population of students and international students represent a high percent (approximately $40 \%$ ) of the graduate student population. A pilot test of the questionnaire was conducted. Eight hospitality and tourism graduate students were asked to respond to the survey to ensure clarity and accuracy. The survey proved to be clear and the students had no problems with the questions. Therefore no changes were made. Following Institutional Review Board (IRB) approval, the graduate school coordinators used a computer application to select a portion of the graduate school population to which online questionnaires by way of qualtrics were randomly sent. The estimated population was about 3500 graduate students. A total of 400 usable questionnaires were answered representing a good response considering the limitations generally in getting response from students, especially with online surveys. The entire population of the graduate school was not used because it's the general policy of the university to only use about one half of the entire graduate population when conducting surveys.

\subsection{Measures}

\subsubsection{Emotional Exhaustion}

A modification of the Maslach Burnout Inventory General Survey (MBI-GS) developed by Schaufeli, Leiter, Maslach, and Jackson (1996) to study burnout was used, not specifically addressing human services. The modified scale MBI-Student Survey (MBI-SS) was used by Schaufeli et al. (1996) in a student sample to measure burnout in terms of emotional exhaustion, cynicism, and efficacy. In the present study, emotional exhaustion will be assessed by the subscale of the MBI-SS. The scale has five items tapping how often students feel emotionally overextended and exhausted by their studies. The scale uses a 7-point frequency rating scale from 0 (never) to 6 (always). Sample items include "Studying or attending class is really a strain for me" and "I feel used up at the end of a day at the university". The higher the scores the more individuals are emotional exhausted. The reliability of the scale is .91 which is above the recommended .7 proposed by Nunnaly and Bernstein (1994). The scale has been validated across student populations in several countries and has been found to be valid enough for the use of this purpose (Schaufeli, et al., 2002)

\subsubsection{Engagement}

Engagement was assessed using the Utrecht Work Engagement Scale for students (UWES-S) (Schaufeli, et al., 2002). This scale was modified from the original (UWES) engagement which was assessed with 17 items (Schaufeli \& Bakker, 2003) on three dimensions: Vigor, 6 items; Dedication, 5 items; and Absorption, 6 items. 
However, the UWES-S contains 14 items (Schaufeli et al., 2002) measured on a similar 7-point frequency rating scale from 0 (never) to 6 (always). The alpha for vigor is .83. Sample items for vigor include "When I am studying, I feel mentally strong". The reliability alpha for dedication was .89. A sample item for dedication includes "My studies inspire me". Reliability alpha for absorption was .80. A sample item for absorption includes: "Time flies when I am studying". Higher scores indicate higher levels of engagement. The composite score of the three scales of engagement (vigor, dedication, and absorption) is often used to represent the concept of engagement. In a study by Kim, Shin and Swanger (2009), the authors utilized the overall score and the individual scores of the three subscales, the results proved to be comparable. In fact, the total scale score may be a better indicator because of the high correlations among the subscales and the possibility of multicollinearity (Schaufeli \& Bakker, 2003; Schaufeli, Bakker, \& Salanova, 2006; Schaufeli, et al., 2002). Similarly, when scales have moderate to high correlations, it is recommended to use a single composite scale (Berry \& Feldman, 1994). The average of the engagement scale was used in the present study. The reliability alpha for this scale is very high at 89 .

The study, however, showed the correlations of all three subscales, indicating moderate to high correlations ranging from .43 to .69 between the engagement subscales. The scale has also undergone validation among Dutch, Spanish and Portuguese student population and is found to be valid for the purpose which it is been used (Schaufeli, et al., 2002).

\subsubsection{Self-Efficacy}

Self efficacy was measured by 6 items of the professional efficacy scale of the Maslach Burnout Inventory-Student Survey adapted from the original MBI-GS (Schaufeli et al. (1996). The items were measured on a 7- point frequency scale from 0 (never) to 6 (always). Examples of items include "I can efficiently solve the problems that arise in my studies" and I feel stimulated when I reach my study goals". Reliability for the scale is .83. Validation of the scale was also conducted among the same Dutch, Soanish and Portuguese student population by Schaufeli, et al. (2002).

\subsubsection{Social Support}

The scale of Perceived Social support (MSPSS) (Zimet, Dahlem, Zimet, \& Farley, 1998) was used to test the amounts of social support received by graduate students. The MPSS is multidimensional and consists of 12 items assessing social support from friends, such as "I can count on my friends when things go wrong", from family, such as "My family really tries to help me"; from significant other, such as "There is a special person who is around when I am in need". Items were scored on a 7-point Likert scale, ranging from 1 (very strongly disagree) to 7 (very strongly agree) for each item. Since advisors should play a major role in graduate student life, five additional questions were incorporated into the social support scale indicating social support from an advisor. Sample items include "I feel I can confide in my advisor" and "I can depend on my advisor to boost my spirits when I feel low". High scores reflect high levels of perceived social support. The scale has high reliability. Reliability alphas in this sample for friends, family, significant other, and advisor are $.93, .90, .96$, and .95 respectively. The scale has been used extensively in measuring social support in various research studies.

\subsubsection{Testing Mediation}

In testing the mediation of engagement between the self efficacy-emotional exhaustion relationship and engagement between social support and emotional exhaustion, the approach suggested by Baron and Kenny (1986) was used. For mediation to occur, certain conditions must be met. First, the independent variable must impact the mediator; that is, self-efficacy and social support must impact engagement. Second, the independent variable must affect the dependent variable. Hence, self-efficacy and social support must impact emotional exhaustion. Third, the mediator must impact the dependent variable. Thus, engagement must affect emotional exhaustion. If the independent variable on the dependent variable in the second step becomes less in the third step, then mediation occurs. If engagement is added to the equation and the effect of self efficacy and social support on emotional exhaustion is reduced, engagement mediates the relationships. If there is no effect when engagement is controlled for, then there is perfect mediation. A follow-up Sobel test was conducted to test the significance of the indirect relationship (Baron \& Kenny, 1986).

\section{Results}

\subsection{Descriptive Statistics}

Descriptive statistics results show that graduate students in the sample are indeed suffering from emotional exhaustion with a more than average mean $(M=4.5, S D$ 1.28). This is more than what was found in two university student samples of Spanish and Dutch students $(M=2.48$ and $M=1.98$ respectively) by Schaufeli and 
Salanova (2007). However, the results were somewhat similar to that of Koeske and Koeske (1991) of social work graduate students $(M=4.30, S D 0.71)$. The reliability coefficients showed that all the main constructs met the minimum alpha level of .70, ranging from .80 to .96 .

Females accounted for 60.3 percent of the sample. Most of the respondents were in the age group of 26-35 which accounted for 52 percent with the next age group of 18-25 accounted for 37 percent. Most of the respondents were unmarried (67.9 percent). Similarly, a large percentage were employed, whether TA/RA or otherwise ( 87.3 percent). This is expected as most of the students were enrolled in Ph.D. programs (64.9 percent). Participants were mostly white (69.6 percent) with the least category Asian American (3 percent). The range of GPAs was from 2.50 to 4.00 .

\subsection{Correlations}

Correlations between the main study variables were conducted. A significant positive relationship was found between self-efficacy and all three engagement subscales (See Table 1). Self-efficacy had a significant negative correlation with emotional exhaustion $(r=-.24 p<.01)$. As expected, the three subscales of engagement were significantly negatively correlated with emotional exhaustion and in the right direction (Table 1) Overall, vigor had the highest correlation with emotional exhaustion $(r=-.439, p<.01)$. Only advisor support had a correlation with all three engagement scales and only advisor support impacted student emotional exhaustion $(r=.256$, $p<.01$ ). (See Table 1 for intercorrelations)

Table 1. Means, standard deviations, and inter-correlations among predictor variables and emotional exhaustion (EE)

\begin{tabular}{lcccccccccccc}
\hline \multicolumn{1}{c}{ Measure } & $\mathbf{M}$ & $\mathbf{S D}$ & $\mathbf{1}$ & $\mathbf{2}$ & $\mathbf{3}$ & $\mathbf{4}$ & $\mathbf{5}$ & $\mathbf{6}$ & $\mathbf{7}$ & $\mathbf{8}$ & $\mathbf{9}$ & $\mathbf{1 0}$ \\
\hline 1. Advisor & 4.67 & 1.69 & - & $.27^{* *}$ & $.24^{* *}$ & $.21^{* *}$ & $.15^{* *}$ & $.27^{* *}$ & $.18^{* *}$ & $-.26^{* *}$ & $.13^{*}$ & $.23^{* *}$ \\
2. Friend & 5.45 & 1.22 & & - & $.41^{* *}$ & $.13^{* *}$ & & $.16^{* *}$ & & & $.30^{* *}$ & \\
3. Family & 5.45 & 1.41 & & & - & $.23^{* *}$ & & $.23^{* *}$ & $.15^{*}$ & & $.36^{* *}$ & $.18^{* *}$ \\
4. Efficacy & 5.36 & .854 & & & & - & $.32^{* *}$ & $.59^{* *}$ & $.38^{* *}$ & $-.24^{* *}$ & & $.53^{* *}$ \\
5. Absorption & 4.27 & 1.16 & & & & & - & $.48^{* *}$ & $.63^{* *}$ & $-.17^{* *}$ & & $.85^{* *}$ \\
6. Dedication & 5.16 & 1.05 & & & & & & - & $.43^{* *}$ & $-.29^{* *}$ & $.15^{*}$ & $.78^{* *}$ \\
7. Vigor & 4.00 & .973 & & & & & & & - & $-.44^{* *}$ & & $.83^{* *}$ \\
8. EE & 4.50 & 1.28 & & & & & & & & - & & $-.36^{* *}$ \\
9. Spouse & 5.48 & 1.71 & & & & & & & & & - & \\
10. Ave-eng & 4.50 & .854 & & & & & & & & & - \\
\hline
\end{tabular}

-All study variables are measures on a 7- point Likert scale (0-6)

- Ave-eng is the average score of the 14 items of the engagement scale of vigor, dedication, and absorption

- ** Correlation is significant at the 0.01 level

- * Correlation is significant at the 0.05 level

\subsection{Results of Hypothesis Testing of Direct and Mediating Effects}

In testing the study variables, hierarchical regression was utilized. Results of the regressions are shown in Tables 2- 5. Findings of the direct effects of the demographic control variables and independent variables of self efficacy and social support on student engagement are presented in Tables 2 and 3. Results indicated that self-efficacy exerted a positive and significant effect on student engagement $(\beta=.56, p<.001)$. Hence, H1 was supported. Similarly, gender had a negative significant relationship with student engagement: males were more engaged than females $(\beta=-.12, p<.05)$. Employment status exerted a significant positive relationship with student engagement. Hence, people who were unemployed were more engaged in their studies $(\beta=.13, p<.05)$. Finally, graduate student type (Masters $/ \mathrm{PhD}$.) $(\beta=.12, p<.05)$ was related to engagement. Students enrolled in PhD. 
programs were more engaged than were Masters students. This significance was found in Step 2 when self efficacy was entered in the model but not in step 1. There was a significant $\Delta \mathrm{R}^{2}$ of .29 .

The result in Table 4 (Step 2) showed that self-efficacy negatively and significantly impacted emotional exhaustion $(\beta=-.19, p<.05)$. Consequently, $\mathbf{H 2}$ was supported. Students who were more self efficacious were less susceptible to emotionally exhaustion. Even though gender, age, and marital status all had a positive significant relationship at Step 1 and Step 2 with emotional exhaustion, only age remained significant in Step 3. Hence, the older the graduate student, the higher his/her emotional exhaustion levels $(\beta=.16, p<.05)$. Results also showed that student engagement had a highly significant negative relationship with emotional exhaustion $(\beta=-.325, p<.001)$. Thus, $\mathbf{H 3}$ was supported. Students who were more engaged in their studies suffered less exhaustion. When engagement was introduced into the model, the direct impact of self-efficacy on emotional exhaustion became insignificant $(\beta=-.01, \mathrm{p}, \mathrm{ns})$; engagement completely mediated the relationship. Thus, H6 is supported. There was a $.07 \Delta \mathrm{R}^{2}$. A Sobel test was conducted to determine whether the indirect effect of self-efficacy on emotional exhaustion by way of engagement was significant. A significant test resulted $(t=-3.88$, $p<.001)$.

In understanding the role of social support on engagement, Table 3, support from family $(\beta=.20, p<.05)$ and advisor $(\beta=.19, p<.05)$ showed a positive and significant relationship with student engagement. Accordingly, students who receive more support from family and advisor were more engaged in their studies. Friends and spouse showed insignificant relationships. Therefore, only H4a and H4d were supported. In the final step (2), only employment status had a positive and significant relationship with engagement. There was a $\Delta \mathrm{R}^{2}$ of .09 .

The result in Table 5 showed that only advisor support had a direct significant negative relationship with emotional exhaustion $(\beta=.29, p<.001)$. The more support received from an advisor, the less exhaustion students experienced. Consequently, only H5d was supported. When engagement was entered into the equation, the size of the direct impact of advisor support on emotional exhaustion was reduced $(\beta=-.24, p<.001)$. Yet, it remained significant with a $\Delta \mathrm{R}^{2}$ of .07. A follow-up Sobel test observed a significant indirect effect $(t=-2.56, p<.05)$. This result suggests a mediating effect. Hence, student engagement partially mediated the advisor support-emotional exhaustion relationship. Therefore, H7d was supported. Similar to engagement, only age had a significant positive impact on emotional exhaustion $(\beta=.17, p<.05)$.

Table 2. Direct effect of self efficacy: Hierarchical regression results

\begin{tabular}{lcc}
\hline Independent variables & $\begin{array}{c}\text { Dependent variable and standardized coefficients (Engagement) } \\
\text { Step 1 }\end{array}$ & $\begin{array}{c}\text { Step 2 } \\
\text { (1) Control variables }\end{array}$ \\
Gender & -.13 & $-.12^{*}$ \\
Age & .00 & .00 \\
Race & .80 & .09 \\
Marital Status & -.07 & -.06 \\
GPA & .09 & -.02 \\
Employment Status & .12 & $.13^{*}$ \\
Graduate Student Type & .03 & $.12^{*}$ \\
(2) Self Efficacy & & $.56^{* *}$ \\
$\mathrm{R}^{2}$ for each step & .06 & .35 \\
$\Delta \mathrm{R}^{2}$ & -- & .29 \\
$\mathrm{~F}$ & 1.97 & $16.14^{* *}$ \\
\hline
\end{tabular}

Additional note applies to tables 2-5: Gender was coded 1 for male and 2 for females. Age was measured using four categories with the lowest being (18-25) to the highest (51 up). Race was categorical: African American, Asian American, Native American, Pacific Islander, White, Hispanic American, Alaskan Native and other. Marital status was dichotomous with $1=$ married and $2=$ not married. GPA was measured on a scale of 
1.00-4.00.Employment status was measured by $1=$ employed; $2=$ unemployed. Graduate student refers to Masters or $\mathrm{PhD}$. level with $1=$ Masters and $2=\mathrm{PhD} .{ }^{*} \mathrm{p}<.05,{ }^{* *} \mathrm{p}<.01$

Table 3. Direct effect of social support: Hierarchical regression results

\begin{tabular}{lcc}
\hline Independent variables & $\begin{array}{c}\text { Dependent variable and standardized coefficients (Engagement) } \\
\text { Step 1 }\end{array}$ & Step 2 \\
\hline (1) Control variables & -.12 & -.11 \\
Gender & .01 & .02 \\
Age & .06 & .04 \\
Race & -.09 & -.06 \\
Marital Status & .08 & .07 \\
GPA & .13 & $.13^{*}$ \\
Employment Status & .01 & .03 \\
Graduate Student Type & & \\
(2) Social Support & & $.30^{*}$ \\
$\quad$ Family & & -.02 \\
$\quad$ Friends & & -.02 \\
$\quad$ Spouse & & $.91^{*}$ \\
$\mathrm{R}^{2}$ for each step & & .14 \\
$\Delta \mathrm{R}^{2} \quad-05$ & .09 \\
$\mathrm{~F} \quad$ & 1.91 & $3.25^{* *}$ \\
\hline
\end{tabular}

Table 4. Hierarchical regression of direct and mediating effect of self efficacy

\begin{tabular}{lccc}
\hline Independent variables & $\begin{array}{c}\text { Dependent variable and standardized coefficients (Emotional Exhaustion) } \\
\text { Step 1 }\end{array}$ & Step 2 & Step 3 \\
\hline (1) Control variables & $.15^{*}$ & $.15^{*}$ & .11 \\
Gender & $.16^{*}$ & $.16^{*}$ & $.16^{*}$ \\
Age & -.08 & -.09 & -.06 \\
Race & $.14^{*}$ & $.13^{*}$ & .11 \\
Marital Status & .07 & -.03 & -.04 \\
GPA & -.06 & -.07 & -.02 \\
Employment Status & .02 & -.01 & .30 \\
Graduate Student Type & & $-.19^{*}$ & -.01 \\
(2) Self Efficacy & & & $-.35^{* *}$ \\
(3) Engagement & .08 & .11 & .18 \\
$\mathrm{R}^{2}$ for each step & -- & .03 & .07 \\
$\Delta \mathrm{R}^{2}$ & 2.82 & $3.67^{* *}$ & $5.69^{* *}$ \\
$\mathrm{~F}$ & & & \\
\hline
\end{tabular}

Sobel test result for: Self efficacy $\rightarrow$ engagement $\rightarrow$ emotional exhaustion $\mathrm{t}=-3.88^{* *}$ 
Table 5. Hierarchical regression of direct and mediating effect of social support

\begin{tabular}{lccc}
\hline Independent variables & $\begin{array}{c}\text { Dependent variable and standardized coefficients } \\
\text { Step 1 }\end{array}$ & Step 2 & Step 3 \\
\hline (1) Control variables & & & \\
Gender & $.15^{*}$ & .10 & .07 \\
Age & $.15^{*}$ & $.16^{*}$ & $.17^{*}$ \\
Race & -.08 & -.06 & -.05 \\
Marital Status & .13 & $.14^{*}$ & .13 \\
GPA & -.07 & -.06 & -.04 \\
Employment Status & -.06 & -.06 & -.02 \\
Graduate Student Type & .31 & .05 & .06 \\
(2) Social Support & & & .06 \\
$\quad$ Family & & -.07 & .09 \\
$\quad$ Friends & & .10 & .05 \\
$\quad$ Spouse & & .06 & $-.24^{* *}$ \\
$\quad$ Advisor & & $-.29^{* *}$ & $.27^{* *}$ \\
(3) Engagement & & & .22 \\
$\mathrm{R}^{2}$ for each step & .07 & .15 & .07 \\
$\Delta \mathrm{R}^{2} \quad$ & -.08 & $5.31^{* *}$ \\
F & & $3.78^{* *}$ & \\
\hline
\end{tabular}

Sobel test result for: Advisor support $\rightarrow$ engagement $\rightarrow$ emotional exhaustion $\mathrm{t}=-2.56^{*}$

\section{Discussion}

The current research attempted to understand the role of self-efficacy, social support, and engagement on graduate students' emotional exhaustion. There is limited literature regarding the importance of student engagement in reducing emotional exhaustion. Extant literature has shown that having engaged employees caused a reduction in employees' stress levels. Consequently, this may similarly be effective in alleviating graduate student emotional exhaustion. The present study represents one of the first studies to understand how the relationship among these constructs impacts masters and doctoral students. Moreover, the graduate student population is susceptible to burnout and, therefore, understanding how it can be reduced should be meaningful for institutions of higher learning. The study also indicates that the newly developed construct of engagement may provide understanding and may help strengthen the social support/self-efficacy-emotional exhaustion relationship which will be beneficial for higher institution policies, procedures, and student management.

First, results show that students who were self-efficacious were more engaged in their studies, indicating that students have high confidence in their capabilities which boosts their engagement. Moreover, social cognitive theory (Bandura, 1997) posited that having increased levels of efficacy equates to motivation which may be likened to high levels of engagement. Engagement constitutes a principal characteristic of motivated behavior (Llorens, et al., 2007). Results shown in the present study are aligned with studies by Luthans and Peterson (2002) and Xanthopoulou et al. (2009) which indicate that having personal resources (self-efficacy) increased employees energy and dedication at work to the point where they become engrossed in the job and cannot detach themselves easily. Males showed higher levels of engagement than females. Unemployed students exhibited more engagement. PhD. students were more engaged than their Masters Degree counterparts. This indicates that attention also may need to be paid to specific student characteristics in an attempt to increase their engagement.

Second, from the results, self-efficacy reduced students' emotional exhaustion. However, when engagement was accounted for, the effect of self-efficacy on students' emotional exhaustion was no longer significant. Hence, when students were self-efficacious, their energy, dedication, and absorption (engagement) in their studies increased thus reducing their exhaustion levels. Students' ages impacted their exhaustion levels with older 
students having higher levels of exhaustion. A possible reason may be that older individuals tend to have more responsibilities and may be less able to cope effectively with the demands of college.

Social support from family and social support from advisor were instrumental in increasing students' engagement. No statistically significant relationships were found for social support from friends and spouse regarding students' engagement. A reason could be that students' friends and spouse tend to be close to them; support received may be adequate for them to be engaged in their studies. On the other hand, graduate students which are mostly international are away from their families and likewise may be detached from advisors which then impact their exhaustion levels.

The findings also demonstrate that student engagement partially mediates the effect between social support from an advisor on emotional exhaustion. Social support from an advisor influences emotional exhaustion directly and indirectly through students' engagement. The finding regarding the direct effect of advisor support on emotional exhaustion coincides with studies by Deery, Iverson, and Walsh (2002). Neumann, Finaly-Neumann, and Reichel (1990) found that student-faculty contact and team leader support reduced student levels of emotional exhaustion. Similarly, engagement was found to mediate the relationship between supervisor support and intention to quit (Saks, 2006) and between supervisor coaching and intention to quit (Schaufeli \& Bakker, 2004). This is somewhat similar to the present study's findings since emotional exhaustion is often a predictor of intention to quit (Deery, Iverson, \& Walsh, 2002; Wright \& Cropanzano, 1998).

\section{Implications of the Study}

Graduate students are often agents of exhaustion which can lead to eventual attrition from graduate programs. This may be caused by the demand of studies coupled with being employed as a teaching or research assistant. In the present study, over $87 \%$ of the students were employed. Institutions of higher learning should endeavor to increase students' self-efficacy and engagement to reduce students' exhaustion levels. This includes having targeted interventions that impact individual characteristics. Older students, for example, were more susceptible to being exhausted than younger ones. Therefore, more support and building older students self-efficacy may increase their engagement in their studies. Colleges may need to have specific programs, such as social interaction programs, where graduate students may interact and support each other through the graduate student process. There also may be a need to have specific programs for older non-traditional students since their needs may be different from younger students. One suggestion is to offer a 'Weekend University' which may be able to meet the needs of these students who work, and have family responsibilities or who may be unable to attend regular day classes. Moreover, advisor support seems to play a crucial role in graduate student exhaustion. An advisor should take a vested interest not only in students' academic life but also their personal and professional development and well being.

While the study did not specifically look at advisor/student ratio, colleges may need to assess its faculty-student ratio. Often advisors are responsible for too many students at once and do not have adequate time to devote to students' needs. College administrators may need to look at policies and guidelines regarding advising so as to maximize the advisor/student relationship. Similarly, colleges may need to consider setting up an overall advising task force where students may get assistance even when their specific advisor may not be available.

Worthy of note is that students with high self-efficacy had lower levels of exhaustion. Colleges may play a role in helping students build their confidence in their capabilities to meet established targets without becoming emotionally exhausted. Advisors and faculty may have students set targeted goals and means to achieve them. Goal setting theory indicates that setting goals enhances performance, as goals have an impact on individual efforts, how persistent they are, and direct their behavior (Hitt, Miller, \& Colella, 2006). When goals are set, students may be more likely to want to achieve them, believing in their efforts and capabilities. Advisors and faculty may reward these behaviors by positive reinforcement which will serve as a basis for increasing student efficacy and impacting their resistance, energy, dedication, and absorption in their studies.

Studies have shown that even verbal praise by professors, such as a simple "great job", is likely to impact graduate students' motivation in a positive way (Hancock, 2002) and build self-efficacy. Additionally, students may be given autonomy and control in executing their work, especially with teaching /research assistants, as well as being provided with feedback.

These have been found to significantly impact engagement in employees in various organizational settings (Bakker, et al., 2005; Schaufeli \& Bakker, 2004). Bandura (1982) indicated that people who are not confident in their abilities to have control over their actions will undermine their efforts in environments taxing their capabilities and may lead to burnout. 
Looking at recruiting practices and strategies in institutions of higher education may be important as well. While there is no clear predictor of how well students will deal with demands of graduate school, colleges and more so specific departments, should make known during recruitment student requirements and conditions that must be fulfilled. This may help students decide if that particular college is suitable for them based on their individual abilities.

Students themselves may take steps to increase their engagement and reduce exhaustion. Students can be assisted by advisor, faculty or college counselors in assessing their work load. They should avoid overload since this may increase their susceptibility to exhaustion. While time management and healthy habits were not measured in this study, developing and practicing effective time management may also enable students to better handle their academic demands. At the same time practicing good health habits may help students better able to cope with college life. Finally, students should endeavor to build personal social networks that may provide additional support beyond the college context.

\section{Future Study and Limitations}

The present study was designed to understand the impact of student engagement, self efficacy, and social support on graduate student emotional exhaustion. The study was conducted at a single university in the Midwest. The students in this sample exhibited above average levels of burnout. It may be prudent to be cautious in generalizing the findings from this study; graduate students at other universities may be exposed to less school demands that may impact their burnout levels. Moreover, the university sampled in the study is a strong research-based institution. Hence, students may be subjected to higher work demands.

Additionally, various universities in other states may be exposed to different environmental conditions which could impact students' behaviors. Future study may want to replicate the present study by extending it to universities in other states or at universities that may be more teaching-based to test if the findings are similar.

The study only looked at graduate level students. Undergraduates are also susceptible to burnout due to extensive coursework. Studies may also want to understand how the concept of engagement, social support, and self-efficacy impact emotional exhaustion with that group of students. A comparison could then be made between graduate and undergraduate students.

Another caution concerns the use of cross sectional data. Difficulty may be encountered to draw causation from this type of data (Cropanzano, Rupp, \& Byrne, 2003). Furthermore, different factors may impact emotional exhaustion over time. Students' exhaustion levels may be different at various time periods during the semester or over a period of time. Conducting future longitudinal studies over various time periods may yield more meaningful results.

One must also acknowledge that only self reported data was collected. Hence, the possibility of common method variance may bias the result. Multiple methods may alleviate this challenge in future studies. It is also noted that some student groups are underrepresented in the study, suggesting bias in the likelihood of students from different cultural backgrounds to participate in such studies.

Finally, the study only used the composite scores of engagement. With the construct measured on three separate dimensions, future studies may test the effects of each dimension separately, to yield better understanding of where specific interventions need to be leveraged to impact engagement.

\section{References}

Attridge, M. (2009). Measuring and managing employee work engagement: A review of the research and business literature. Journal of Workplace Behavioral Health, 24(4), 383-398. http://dx.doi.org/10.1080/15555240903188398

Bakker, A. B., Demerouti, E., \& Euwema, M. C. (2005). Job resources buffer the impact of job demands on $\begin{array}{lllll}\text { burnout. Journal of Occupational Health Psychology, } & 10(2), & 170 .\end{array}$ http://dx.doi.org/10.1037/1076-8998.10.2.170

Balogun, A. J., Helgemoe, S., Pellegrini, E., \& Hoeberlein, T. (1995). Test-retest reliability of a psychometric instrument designed to measure physical theraphy students'burnout. Economic Record, 81(2), 667-672.

Bandura, A. (1982). Self-efficacy mechanism in human agency. American psychologist, 37(2), 122. http://dx.doi.org/10.1037/0003-066X.37.2.122

Bandura, A. (1997). Self-efficacy: The exercise of control. Worth Publishers. http://dx.doi.org/10.1002/9780470479216.corpsy0836 
Baron, R. M., \& Kenny, D. A. (1986). The moderator-mediator variable distinction in social psychological research: Conceptual, strategic, and statistical considerations. Journal of personality and social psychology, 51(6), 1173. http://dx.doi.org/10.1037/0022-3514.51.6.1173

Berry, W. D., \& Feldman, S. (1994). Multiple regression in practice (Vol. 50). Sage.

Cordes, C. L., \& Dougherty, T. W. (1993). A review and an integration of research on job burnout. Academy of management review, 621-656. http://dx.doi.org/10.5465/AMR.1993.9402210153

Crawford, E. R., LePine, J. A., \& Rich, B. L. (2010). Linking job demands and resources to employee engagement and burnout: A theoretical extension and meta-analytic test. Journal of Applied Psychology, 95(5), 834. http://dx.doi.org/10.1037/a0019364

Cropanzano, R., Rupp, D. E., \& Byrne, Z. S. (2003). The relationship of emotional exhaustion to work attitudes, job performance, and organizational citizenship behaviors. Journal of Applied Psychology, 88(1), 160. http://dx.doi.org/10.1037/0021-9010.88.1.160

Deery, S., Iverson, R., \& Walsh, J. (2002). Work relationships in telephone call centres: Understanding emotional exhaustion and employee withdrawal. Journal of Management Studies, 39(4), 471-496. http://dx.doi.org/10.1111/1467-6486.00300

Fives, H., Hamman, D., \& Olivarez, A. (2007). Does burnout begin with student-teaching? Analyzing efficacy, burnout, and support during the student-teaching semester. Teaching and Teacher Education, 23(6), 916-934. http://dx.doi.org/10.1016/j.tate.2006.03.013

Freudenberger, H. J. (1974). Staff burn-out. Journal of social issues, 30(1), 159-165. http://dx.doi.org/10.1111/j.1540-4560.1974.tb00706.x

Friedman, I. A. (2003). Self-efficacy and burnout in teaching: The importance of interpersonal-relations efficacy. Social Psychology of Education, 6(3), 191-215. http://dx.doi.org/10.1023/A:1024723124467

Gaines, J., \& Jermier, J. M. (1983). Emotional exhaustion in a high stress organization. Academy of Management Journal, 567-586. http://dx.doi.org/10.2307/255907

Gold, Y., Bachelor, P., \& Michael, W. B. (1989). The dimensionality of a modified form of the Maslach Burnout Inventory for university students in a teacher-training program. Educational and Psychological Measurement, 49(3), 549-561. http://dx.doi.org/10.1177/001316448904900305

Golde, C. (2005). The role of the department and discipline in doctoral student attrition: Lessons from four departments. The Journal of Higher Education, 76(6). http://dx.doi.org/10.1353/jhe.2005.0039

Hancock, D. R. (2002). Influencing graduate students' classroom achievement, homework habits and motivation to learn with verbal praise. Educational Research, 44(1), 83-95. http://dx.doi.org/ $10.1080 / 00131880110107379$

Harter, J. K., Schmidt, F. L., \& Hayes, T. L. (2002). Business-unit-level relationship between employee satisfaction, employee engagement, and business outcomes: A meta-analysis. Journal of Applied Psychology, 87(2), 268-279. http://dx.doi.org/10.1037/0021-9010.87.2.268

Hitt, M. A., Miller, C. C., \& Colella, A. (2006). Organizational behavior a strategic approach. Wiley-India.

House, J. S. (1981). Work stress and social support. Addison-Wesley Pub. Co.

Ito, J. K., \& Brotheridge, C. M. (2003). Resources, coping strategies, and emotional exhaustion: A conservation of resources perspective. Journal of Vocational Behavior, 63(3), 490-509. http://dx.doi.org/10.1016/S0001-8791(02)00033-7

Jacobs, S. R., \& Dodd, D. (2003). Student burnout as a function of personality, social support, and workload. Journal of College Student Development, 44(3), 291-303. http://dx.doi.org/10.1353/csd.2003.0028

Johnson, B., Batia, A., \& Haun, J. (2008). Perceived stress among graduate students: Roles, responsibilities, and social support. VAHPERD Journal Spring, 31-35.

Kahn, W. A. (1990). Psychological conditions of personal engagement and disengagement at work. The Academy of Management Journal, 33(4), 692-724. http://dx.doi.org/10.2307/256287

Karatepe, O., \& Olugbade, O. (2009). The effects of job and personal resources on hotel employees' work engagement. International Journal of Hospitality Management, 28(4), 504-512. http://dx.doi.org/10.1016/j.ijhm.2009.02.003 
Kim, H., Shin, K., \& Swanger, N. (2009). Burnout and engagement: A comparative analysis using the Big Five personality dimensions. International Journal of Hospitality Management, 28(1), 96-104. http://dx.doi.org/10.1016/j.ijhm.2008.06.001

Klusmann, U., Kunter, M., Trautwein, U., Lüdtke, O., \& Baumert, J. (2008). Engagement and emotional exhaustion in teachers: Does the school context make a difference? Applied Psychology, 57, 127-151. http://dx.doi.org/10.1111/j.1464-0597.2008.00358.x

Koekse, R. D., \& Koeske, G. F. (1989). Working and Non-Working Students: Roles, Support and Well-Being. Journal of Social Work Education, 25(3), 244-256.

Koeske, G. F., \& Koeske, R. D. (1991). Student "burnout" as a mediator of the stress-outcome relationship. Research in Higher Education, 32(4), 415-431. http://dx.doi.org/ 10.1007/BF00992184

Llorens, S., Schaufeli, W., Bakker, A., \& Salanova, M. (2007). Does a positive gain spiral of resources, efficacy beliefs and engagement exist? Computers in human behavior, 23(1), 825-841. http://dx.doi.org/10.1016/j.chb.2004.11.012

Luthans, F., \& Peterson, S. (2002). Employee engagement and manager self-efficacy. Journal of Management Development, 21(5), 376-387. http://dx.doi.org/ 10.1108/02621710210426864

Maslach, C. (2003). Burnout: The cost of caring. Ishk Book Service.

Maslach, C., \& Leiter, M. P. (1997). The truth about burnout: How organizations cause personal stress and what to do about it (Vol. 186). Jossey-Bass.

Meier, S. T., \& Schmeck, R. (1985). The burned-out college student: A descriptive profile. Journal of College Student Personnel, 26(1), 63-69.

Moore, J. E. (2000). One road to turnover: An examination of work exhaustion in technology professionals. Mis Quarterly, 141-168.

Neumann, Y., Finaly-Neumann, E., \& Reichel, A. (1990). Determinants and consequences of students' burnout in universities. The Journal of Higher Education, 20-31.

Offstein, E. H., Larson, M. B., McNeill, A. L., \& Mwale, H. M. (2004). Are we doing enough for today's graduate student? International Journal of Educational Management, 18(7), 396-407. http://dx.doi.org/10.1108/09513540410563103

Ramist, L. (1981). College student attrition and retention. College Entrance Examination Board New York.

Riggio, R. E., \& Porter, L. W. (2003). Introduction to industrial/organizational psychology. Prentice Hall.

Saks, A. (2006). Antecedents and consequences of employee engagement. Journal of Managerial Psychology, 21(7), 600-619. http://dx.doi.org/10.1108/02683940610690169

Sarason, I. G., Levine, H. M., Basham, R. B., \& Sarason, B. R. (1983). Assessing social support: The social support questionnaire. Journal of personality and social psychology, 44(1), 127. http://dx.doi.org/10.1037/0022-3514.44.1.127

Schaufeli, \& Bakker, A. B. (2004). Job demands, job resources, and their relationship with burnout and engagement: A multi sample study. Journal of organizational Behavior, 25(3), 293-315. http://dx.doi.org/10.1002/job.248

Schaufeli, Salanova, M., González-Romá, V., \& Bakker, A. B. (2002). The measurement of engagement and burnout: A two sample confirmatory factor analytic approach. Journal of Happiness studies, 3(1), 71-92. http://dx.doi.org/ 10.1023/A:1015630930326

Schaufeli, W., \& Bakker, A. (2003). Utrecht work engagement scale: Preliminary manual. Occupational Health Psychology Unit, Utrecht University, Utrecht.

Schaufeli, W., \& Salanova, M. (2007). Efficacy or inefficacy, that's the question: Burnout and work engagement, and their relationships with efficacy beliefs. Anxiety Stress and Coping, 20(2), 177. http://dx.doi.org/10.1080/10615800701217878

Schaufeli, W. B., Bakker, A. B., \& Salanova, M. (2006). The measurement of work engagement with a short $\begin{array}{llll}\text { questionnaire. Educational and Psychological Measurement, } & 66(4), & \end{array}$ http://dx.doi.org/10.1177/0013164405282471 
Schaufeli, W. B., Martínez, I. M., Pinto, A. M., Salanova, M., \& Bakker, A. B. (2002). Burnout and engagement in university students. Journal of cross-cultural Psychology, 33(5), 464. http://dx.doi.org/10.1177/0022022102033005003

Schaufeli., \& Bakker, A. B. (2004). Job demands, job resources, and their relationship with burnout and engagement: A multi sample study. Journal of organizational Behavior, 25(3), 293-315. http://dx.doi.org/10.1002/job.248

Schmitz, G. S. (2000). Variations structure and dynamics of teacher self-efficacy. A protective factor against strain and burnout? Retrieved from http://www.diss.fu-berlin.de/diss/receive/Fudiss_thesis_000000000315

Slåtten, T., \& Mehmetoglu, M. (2011). Antecedents and effects of engaged frontline employees: A study from the hospitality industry. Managing Service Quality, 21(1), 88-107. http://dx.doi.org/10.1108/09604521111100261

Wright, T. A., \& Cropanzano, R. (1998). Emotional exhaustion as a predictor of job performance and voluntary turnover. Journal of Applied Psychology, 83(3), 486. http://dx.doi.org/ 10.1037/0021-9010.83.3.486

Xanthopoulou, D., Bakker, A. B., Demerouti, E., \& Schaufeli, W. B. (2009). Reciprocal relationships between job resources, personal resources, and work engagement. Journal of Vocational Behavior, 74(3), $235-244$. http://dx.doi.org/10.1016/j.jvb.2008.11.003

Yang, H. J., \& Farn, C. K. (2005). An investigation the factors affecting MIS student burnout in technical-vocational college. Computers in human behavior, 21(6), 917-932. http://dx.doi.org/10.1016/j.chb.2004.03.001

\section{Copyrights}

Copyright for this article is retained by the author(s), with first publication rights granted to the journal.

This is an open-access article distributed under the terms and conditions of the Creative Commons Attribution license (http://creativecommons.org/licenses/by/3.0/). 